\title{
ANALISIS DAN OPTIMALISASI PERSEDIAAN BAHAN BAKAR PEMBANGKIT LISTRIK PADA PT. KUTILANG PAKSI MAS DENGAN METODE ECONOMIC ORDER QUAANTITY (EOQ).
}

\author{
${ }^{1}$ Mohamad Fadly, ${ }^{2}$ A. I. Jaya, ${ }^{3}$ A. Sahari \\ 1,2,3 Program Studi Matematika Jurusan Matematika FMIPA UniversitasTadulako \\ Jalan Soekarno-Hatta Km. 09 Tondo, Palu 94118, Indonesia. \\ 1Fadlymohamad23@gmail.com,2ratianingsih@yahoo.com,3agus_sh@yahoo.com
}

\begin{abstract}
PT. Kutilang Paksi Mas (KPM) Palu is a energy company, that is a electric generator. In the conducting production, it associated with supplies of fuel oil. The supplies is one of the management activity which related to the cost of storage and ordering, so that the analysis and optimization of supply is necessary. In this study the authors using Economic Order Quantity to analyze and to optimize the supply. From the analysis that has been done, it can be concluded that by using the EOQ method, the results is more efficient. This can be seen from one reservations is $25.065,75$ liters, and with the number of reservations as many as 365 times for each year and the total cost of supply Rp. $762.831 .650,68$,- while when using the EOQ method, the ordering number is $43.831,13$ liters, and with the number of reservations as many as 209 times for each year and the total cost of supply Rp. $657.466 .959,63,-$. The safety stock that be held PT. KPM according to the EOQ method is $320.931,33$ liters, while the reorder point is $345.997,09$ liters.
\end{abstract}

Keyword : : Analysis, Supply, EOQ Methods, Optimization

\section{ABSTRAK}

PT. Kutilang Paksi Mas (KPM) Palu merupakan perusahaan yang bergerak dalam bidang energi, yaitu pembangkit listrik. Dalam melakukan kegiatan produksinya sangat berkaitan dengan persediaan Bahan Bakar Minyak. Persediaan merupakan salah satu kegiatan manajemen yang berhubungan dengan biaya penyimpanan dan pemesanan sehingga diperlukan analisis dan optimalisasi persediaan. Dalam penelitian ini penulis menggunakan metode Economic Order Quantity untuk menganalisis dan mengoptimalkan persediaan tersebut. Dari hasil analisis yang telah dilakukan maka dapat diperoleh kesimpulan bahwa dengan menggunakan metode EOQ hasilnya lebih efisien. Hal ini dapat dilihat dengan jumlah pemesanan setiap kali pesan sebesar 25.065,75 liter dengan jumlah pemesanan sebanyak 365 kali setiap tahun dan total biaya persediaannya sebesar Rp.762.831.650,68,- sedangkan bila menggunakan metode EOQ jumlah pemesanannya sebesar 43.831,13 liter dengan jumlah pemesanan sebanyak 209 kali setiap tahun dan total biaya persediaannya sebesar Rp. 657.466.959,63,-. Persediaan Pengaman yang harus diadakan PT. Kutilang Paksi Mas menurut metode EOQ adalah 320.931,33 liter, sedangkan titik pemesanan kembali adalah 345.997,09 liter.

Kata Kunci : : Analisis, Persediaan, Metode EOQ, Optimalisasi. 


\section{PENDAHULUAN}

\subsection{Latar Belakang}

Seiring dengan perkembangan zaman, Bahan Bakar Minyak (BBM) semakin dibutuhkan di Indonesia khususnya di Kota Palu. Salah satu pengguna BBM tersebut adalah Pembangkit Listrik Tenaga Diesel (PLTD). Dengan adanya peningkatan kebutuhan terhadap BBM dari semua kalangan menyebabkan perusahaan pembangkit listrik tenaga diesel harus melakukan persediaan, khususnya persediaan BBM.

Jumlah persediaan tidak dalam jumlah terlalu banyak dan tidak terlalu sedikit karena keduanya mengandung resiko. Terlalu sedikit dapat berpeluang terjadinya kehabisan persediaan yang berakibat berhentinya proses kerja pembangkit listrik. Dilain pihak apabila jumlah persediaan terlalu banyak, berarti terlalu besar modal kerja yang terikat pada aset sehingga butuh gudang yanag besar dengan resiko biaya pergudangan menjadi tinggi.

Economic Order Quantity (EOQ) adalah salah satu metode dalam manajemen persediaan yang klasik dan sederhana. Perumusan metode EOQ pertama kali diperkenalkan Oleh F.W. Harris pada tahun 1915, tetapi metode ini sering disebut EOQ Wilson karena metode ini dikembangkan oleh seorang peneliti bernama Wilson pada tahun 1934. Metode ini digunakan untuk menghitung minimalisasi total biaya persediaan berdasarkan rumus tingkat atau titik Equlibrium kurva biaya simpan dan biaya pesan (Kusuma, 2009).

PT Kutilang Paksi Mas (KPM) didirikan pada tahun 1997. Perusahaan ini bergerak dalam bidang energi minyak dan gas. PT KPM telah ada di Kota Palu sejak tanggal 29 April 2012. Dikota palu PT KPM mengelolah salah satu pembangkit listrik tenaga diesel. Perusahaan ini harus menjaga persediaan yang ekonomis jika persediaan terlalu sedikit maka perusahaan tersebut beresiko mengalami kehabisan BBM yang berakibat tidak tersedianya aliran listrik di sebagian Kota Palu atau jika terlalu banyak persediaan mengakibatkan terlalu banyak modal yang terpakai untuk penyimpanan. Berdasarkan pembahasan diatas maka penulis tertarik untuk membuat penelitian dengan judul "ANALISIS DAN OPTIMALISASI PERSEDIAAN BAHAN BAKAR PEMBANGKIT LISTRIK PADA PT KUTILANG PAKSI MAS DENGAN METODE ECONOMIC ORDER QUANTITY (EOQ)".

\subsection{Rumusan Masalah}

Permasalahan dalam penelitian ini adalah bagaimana menentukan persediaan dan biaya total persediaan BBM jenis solar yang ekonomis pada PT Kutilang Paksi Mas dengan menggunakan metode Economic Order Quantity (EOQ). 


\subsection{Tujuan Penelitian}

Tujuan penelitian ini adalah untuk menentukan jumlah persediaan dan biaya total persediaan BBM Jenis Solar yang ekonomis pada PT Kutilang Paksi Mas melalui metode Economic Order Quantity (EOQ).

\subsection{Manfaat Peneltian}

Manfaat yang dapat diambil dari penelitian ini adalah:

1. Mengetahui jumlah persediaan dan biaya total persediaan BBM Jenis Solar yang ekonomis pada PT Kutilang Paksi Mas dengan melalui metode Economic Order Quantity (EOQ).

2. Dengan penelitian ini diharapkan dapat menjadi referensi untuk penelitian lebih lanjut.

\subsection{Batasan Masalah}

1. Penelitian dibatasi pada penggunaan BBM jenis solar satu periode yaitu pada tahun 2014.

2. Data yang diambil dalam penelitian ini hanya data kuantitatif yaitu berupa :
a. Jumlah pemesanan BBM dalam satu periode.
b. Biaya pemesanan BBM dalam satu periode.
c. Harga BBM perliter.

\subsection{Asumsi Penelitian}

1. BBM yang dipesan dan disimpan hanya satu macam.

2. Kebutuhan BBM diketahui dan konstan.

3. Biaya pemesanan dan biaya penyimpanan diketahui dan konstan.

4. BBM yang dipesan, di terima dalam satu kelompok.

5. Harga BBM per liter tetap dan tidak bergantung dari jumlah yang dibeli.

6. Waktu tenggang diketahui dan konstan.

\section{METODE PENELITIAN}

\subsection{Prosedur Penelitian}

Prosedur dari penelitian ini adalah sebagai berikut:

1. Melakukan studi literatur dengan mengumpulkan materi dari buku-buku, artikel, dan jurnal yang didapat dari perpustakaan dan perpustakaan online.

2. Menganalisa masalah.

3. Memulai penelitian.

4. Pengambilan data. 
5. Menentukan variable dari setiap masalah.

6. Menentukan model matematis.

7. Menyelesaikan model menggunakan metode EOQ.

8. Menyimpulkan hasil penelitian.

9. Selesai.

\subsection{Metode yang Digunakan}

\section{Metode Economic Order Quantity (EOQ)}

EOQ merupakan metode persediaan yang menentukan jumlah pemesanan berdasarkan biaya pemesanan dan penyimpanan yang minimal atau dengan kata lain EOQ merupakan volume atau jumlah pembelian yang ekonomis untuk dilaksanakan pada setiap pembelian (P. Siagian, 1987).

\section{Perumusan Metode EOQ}

Model EOQ yang telah dijelaskan sebelumnya dapat diterapkan bila anggapananggapan berikut terpenuhi:

a. Hanya satu barang yang di perhitungkan.

b. Kebutuhan (permintaan) setiap periode diketahui, relatif tetap dan terus menerus.

c. Barang yang dipesan diasumsikan langsung dapat tersedia atau berlimpah.

d. Waktu tenggang (lead time) bersifat konstan.

e. Setiap pesanan diterima dalam sekali pengiriman dan langsung dapat digunakan.

f. Tidak ada pesanan ulang (back order) karena kehabisan persediaan.

g. Tidak ada quantity discount.

(Nasution, Arman H. dan Prasetyawan, 2008)

\section{Persediaan Pengaman}

Persediaan pengaman sering juga disebut sebagai persediaan besi (iron stock) adalah suatu persediaan yang dicadangkan sebagai pengaman dari kelangsungan proses produksi perusahaan untuk menghindari terjadinya kekurangan barang. Persediaan pengaman ini merupakan sejumlah unit tertentu dimana unit ini akan tetap dipertahankan walau bahan bakunya dapat berganti dengan yang baru. Untuk menentukan persediaan pengaman ini dipergunakan analisis satatistik dengan melihat dan memperhitungkan penyimpangan-penyimpangan yang sudah terjadi antara perkiraan bahan baku dengan pemakaian sesungguhnya dapat diketahui besarnya standar dari penyimpangan tersebut. Manajemen perusahaan akan menentukan 
seberapa jauh penyimpangan-penyimpangan yang terjadi tersebut agar dapat ditolerir. Jika persediaan pengaman terlalu banyak akan mengakibatkan perusahaan menanggung biaya penyimpangan terlalu mahal. Oleh karena itu, perusahaan harus dapat menentukan besarnya persediaan pengaman secara tepat.

Persediaan pengaman berfungsi untuk melindungi atau menjaga kemungkinan terjadinya kekurangan barang, misalnya karena penggunaan barang yang lebih besar dari perkiraan semula atau keterlambatan dalam penerimaan barang yang dipesan. (Herjanto, 1999)

\section{Pemesanan Kembali \\ Saat harus diadakan pemesanan kembali sehingga kedatangan atau} penerimaan barang yang dipesan tepat waktu (di mana persediaan di atas persediaan pengaman sama dengan nol). Titik pemesanan ulang dapat ditetapkan dengan menjumlahkan penggunaan selama waktu tenggang ditambah dengan persediaan pengaman. (Herjanto, 1999)

5. Total Inventory Cost

Merupakan total keseluruhan dari biaya-biaya yang timbul akibat dari persediaan yang dikeluarkan oleh perusahaan.

\section{HASIL DAN PEMBAHASAN}

\subsection{Data Penelitian}

Persediaan Bahan Bakar Minyak (BBM) yang dilakukan oleh PT Kutilang Paksi Mas (KPM) harus benar-benar terpenuhi agar pasokan listrik untuk masyarakat kota Palu lebih baik. Dalam pengendalian persediaannya PT KPM melakukan pemesanan BBM setiap hari dengan kuantitas pemesanan tetap berdasarkan rata-rata kebutuhan pemakaian BBM setiap harinya. Dalam penelitian ini hal yang akan dibandingkan adalah total biaya persediaan menurut kebijakan perusahaan dengan total biaya persediaan dengan menggunakan metode EOQ dalam kurun periode tahun 2014. Dengan mengetahui jumlah pemakaian BBM, harga bahan bakar, biaya pemesanan, biaya penyimpanan, dan waktu tenggang (lead time).

Metode perhitungan EOQ dilakukan untuk mengetahui berapa jumlah kuantitas pemesanan dan total biaya persediaan optimum dari biaya-biaya operasionalnya. Melalui metode $E O Q$, perusahaan mampu menentukan jumlah persediaan pengaman yang harus ada di perusahaan untuk menjaga keterlambatan pasokan bahan bakar. Selai itu, metode 
EOQ juga dapat membantu perusahaan untuk dapat menentukan kapan titik pemesanan kembali harus dilakukan.

PT Kutilang Paksi Mas (KPM) melakukan pemesanan bahan bakar terhitung setiap hari. Data yang diperoleh dari perusahaan tersebut dapat dilihat pada tabel di bawah ini.

Tabel 1. Data Persediaan Bahan Bakar Tahun 2014

\begin{tabular}{|c|l|c|}
\hline NO. & \multicolumn{1}{|c|}{ BULAN } & PERSEDIAAN (Liter) \\
\hline 1 & Mei & 942.000 \\
\hline 2 & Juni & 915.000 \\
\hline 3 & Juli & 774.000 \\
\hline 4 & Agustus & 913.000 \\
\hline 5 & September & 974.000 \\
\hline 6 & Oktober & 379.000 \\
\hline 7 & November & 1.045 .000 \\
\hline 8 & Desember & 791.000 \\
\hline 9 & Januari & 610.000 \\
\hline 10 & Februari & 637.000 \\
\hline 11 & Maret & 606.000 \\
\hline 12 & April & 563.000 \\
\hline \multirow{2}{*}{} & Jumlah(D) & 9.149 .000 \\
\cline { 2 - 3 } & Rata-rata & $762.416,67$ \\
\hline
\end{tabular}

Sumber : PT. Kutilang Paksi Mas

\subsection{Analisis Pengendalian Persediaan Berdasarkan Kebijakan Perusahaan}

\subsubsection{Komponen biaya persediaan}

Berdasarkan analisis biaya persediaan bahan bakar minyak (BBM) terdapat tiga komponen biaya, yaitu biaya pemesanan, biaya penyimpanan, dan harga BBM per liter. Komponen biaya persediaan bahan bakar minyak pada PT Kutilang Paksi Mas disajikan pada tabel berikut.

Tabel 2. Data Biaya Persediaan Per Satu Kali Pesan

\begin{tabular}{|l|l|}
\hline Biaya Pemesanan $(\mathrm{S})$ & Rp 1.574.900,-- \\
\hline Biaya Penyimpanan $(\mathrm{H})$ & Rp 15.000,- \\
\hline Harga Perliter $(\mathrm{C})$ & Rp 11.500,- \\
\hline Lead Time $(\mathrm{L})$ & 1 Hari \\
\hline
\end{tabular}

Sumber : Hasil Olahan Dari PT. Kutilang Paksi Mas 


\subsubsection{Frekuensi Pemesanan}

Frekuensi pemesanan (F) merupakan banyaknya pemesanan bahan bakar dalam setahun yang dilakukan oleh PT KPM. Dalam hal ini PT. KPM melakukan pemesanan bahan bakar setiap hari selama setahun dengan asumsi dalam setahun terdapat 365 hari. Jadi frekuensi pemesanan bahan bakar yang dilakukan PT. KPM adalah sebanyak 365 kali dalam setahun.

\subsubsection{Total Biaya Persediaan Menurut Kebijakan Perusahaan}

1. Jumlah Pemesanan Bahan Bakar Per Pesan

Berdasarkan komponen biaya yang dipengaruhi oleh persediaan seperti yang telah dijelaskan sebelumnya, maka kita dapat mengetahui total biaya persediaan yang dikeluarkan PT. Kutilang Paksi Mas.

$$
\mathrm{Q}=\frac{\square}{\square} \frac{D}{F}
$$

Jadi, besarnya jumlah pemesanan bahan bakar yang dilakukan oleh PT. Kutilang Paksi Mas dalam sekali pesan adalah sebesar 25.065,75 liter per pesan.

\section{Total Biaya Persediaan Perusahaan (total inventory cost) \\ Dengan mengetahui biaya-biaya persediaan diatas, maka dapat} dihitung total biaya persediaan perusahaan sebagai berikut:

Biaya pemesanan per tahun $=\frac{\square}{\square} \square \frac{D}{Q} S$

Biaya penyimpanan pertahun $=\frac{Q}{2} H$

Dari hasil perhitungan mengguunakan rumus (2) dan (3) dapat diketahui biaya pemesanan per tahun adalah Rp. 574.838 .500 ,- dan biaya penyimpanan per tahun adalah Rp. 187.993.150,68,-. Untuk mengetahui total biaya persediaan Perusahaan dapat dihitung dengan rumus sebgai berikut :

$$
\mathrm{TIC}=\left[\frac{D}{Q} S\right]+\left[\frac{Q}{2} H\right]
$$

Dari perhitungan menggunakan rumus (4) dapat diketahui total biaya persediaan yang harus ditanggung perusahaan selama setahun adalah Rp. 762.831.650,68,-. 


\subsection{Analisis Pengendalian Persediaan Berdasarkan Metode EOQ}

\subsubsection{Menghitung Jumlah Pemesanan Bahan Bakar Menurut Metode EOQ}

Jumlah pemesanan bahan bakar yang ekonomis menggunakan metode EOQ

$\left(Q^{*}\right)$ adalah :

$Q^{*}=\sqrt{\frac{2 D S}{H}}$

Dari perhitungan menggunakan rumus (5) dapat diketahui jumlah pemesanan bahan bakar yang ekonomis menurut metode EOQ untuk PT KPM adalah sebesar 43.831,13 liter per pesan.

\subsubsection{Frekuensi Pemesanan}

Dalam menghitung frekuensi pemesanan digunakan jumlah pemesanan bahan bakar yang ekonomis dengan rumus berikut :

$F=\frac{D}{Q^{*}}$

Dari perhitungan menggunakan rumus (6) dapat diketahui frekuensi pemesanan bahan bakar dengan menggunakan metode EOQ adalah sebanyak 209 kali per tahun.

\subsubsection{Persediaan Pengaman (safety stock)}

Dalam penelitian ini menghitung persediaan pengaman digunakan metode statistik dengan membandingkan rata-rata pemesanan bahan bakar dengan pemesanan bahan bakar yang sesungguhnya kemudian dicari penyimpangannya.

$\sigma=\sqrt{\frac{\sum(x-\bar{x})^{2}}{n}}$

Berdasarkan perhitungan penggunaan bahan bakar mengunakan rumus (7) diperoleh standar deviasi yaitu $\sigma=194.503,8382$. Dan PT. KPM menggunakan batas toleransi $\alpha=5 \%$ dibawah perkiraan dan diperoleh nilai standar normal deviasi (Z) adalah 1,65. Maka besarnya persediaan pengaman (safety stock) bahan bakar dapat dihitung dengan rumus sebgai berikut:

$S S=Z \sigma$ 
Dimana, SS = Safety Stock (persediaan pengaman)

$Z=$ standar deviasi

$\sigma=$ standar deviasi normal

Dari hasil perhitungan menggunakan rumus (8) dapat diketahui persediaan pengaman (safety stock) bahan bakar yang harus disediakan oleh PT. KPM pada tahun 2014 adalah 320.931,33 liter.

\subsubsection{Pemesanan Kembali (reorder point)}

Rata-rata penggunaan bahan bakar perhari (d) pada PT KPM adalah 365 hari.. Dalam melakukan pemesanan bahan bakar PT KPM memiliki waktu tenggang (lead time) (L) selama 1 hari untuk menunggu kedatangan bahan bakar setelah terjadi pemesanan. Maka titik pemesanan kembali dapat dihitung dengan rumus sebagai berikut :

$\mathrm{ROP}=\mathrm{dL}+\mathrm{SS}$

Dari hasil perhitungan menggunakan rumus (9) dapat diketahui bahwa titik pemesanan kembali bahan bakar berada pada 345.997,09 liter.

\subsubsection{Total Biaya Persediaan ( Total Inventory Cost)}

Dari variabel-variabel yang telah disebutkan sebelumnya, total biaya persediaan dapat dihitung sebagai berikut :

$\mathrm{TIC}=\sqrt{2 D S H}$

Dari perhitungan menggunakan rumus (10) total biaya persediaan (total inventory cost) perusahaan menggunakan metode EOQ yaitu sebesar Rp 657.466.959,63,-

\subsection{Perbandingan Kebijakan Perusahaan Dengan Metode EOQ}

Perbandingan antara jumlah pemesanan bahan bakar, frekuensi pemesanan, dan total biaya persediaan menurut kebijakan perusahan berbandingan dengan penggunaan metode EOQ diperlihatkan pada tabel 4. 
Tabel 4. Perbandingan Kebijakan Perusahaan Dengan Metode EOQ

\begin{tabular}{|c|c|c|c|}
\hline NO & Keterangan & Kebijakan Perusahaan & Metode EOQ \\
\hline 1 & Jumlah pemesanan BBM & $25.065,75$ liter. & $43.831,13$ liter. \\
\hline 2 & Total Biaya Persediaan & Rp.762.831.650,68,- & Rp. 657.466.959,63,- \\
\hline 3 & Frekuensi Pemesanan & 365 kali & 209 kali \\
\hline 4 & Persediaan Pengaman & - & $320.931,33$ liter. \\
\hline 5 & Pemesanan Kembali & - & $345.997,09$ liter. \\
\hline
\end{tabular}

\section{Kesimpulan}

Dari hasil penelitian dan pembahasan pada bab sebelumnya, dapat diambil suatu kesimpulan sebagai berikut:

1. Frekuensi pemesanan bahan bakar PT Kutilang Paksi Mas bila menggunakan metode EOQ adalah 209 kali pemesanan bahan bakar dalam satu periode (1 tahun). Sedangkan kebijakan perusahaan adalah 365 kali dalam satu tahun.

2. Total biaya persediaan bahan bakar solar perusahaan bila dihitung menurut EOQ adalah sebesa Rp. 657.466.959,63,-- sedangkan kebijakan perusahaan Rp.762.831.650,68,-

3. Jumlah pemesanan setiap kali pesan adalah $25.065,75$ liter, sedangkan menggunakan EOQ adalah $43.831,13$ liter

4. PT Kutilang Paksi Mas tidak menetapkan adanya persediaan pengaman dalam kebijakannya, sedangkan dalam metode $E O Q$, perusahaan harus mengadakan persediaan pengaman untuk memperlancar pasokan listrik untuk masyarakat dengan jumlah 320.931,33 liter.

5. Adanya titik pemesanan kembali (reorder point) dalam metode EOQ untuk mengantisipasi keterlambatan pengiriman bahan bakar. Menurut metode EOQ, perusahaan harus melakukan pemesanan bahan bakar kembali saat persediaan bahan bakar berada pada titik jumlah sebesar 345.997,09 liter.

\section{DAFTAR PUSTAKA}

[1]. Herjanto, Eddy. Manajemen Produksi dan Operasi. Grasindo. 1999. Jakarta.

[2]. Nasution, Arman H. dan Prasetyawan, Yudha. Perencanaan \& Pengendalian Produksi. Graha IImu. 2008. Yogyakarta.

[3]. P, Siagian. Penelitian Operasional Teori dan Praktek. Universitas Indonesia. 1987. Jakarta.

[4]. PT. Kutilang Paksi Mas. 2014. Palu 